\title{
El largo camino hacia la indexación de la Revista Argentina de Cardioangiología Intervencionista
}

\author{
The long way towards the indexation of the Revista Argentina de \\ Cardioangiología Intervencionista
}

Revista Argentina de Cardioangiología Intervencionista 2017;8(3):110

Desde el inicio de la publicación de la Revista Argentina de Cardioangiología Intervencionista (RACI), fue mucho el camino recorrido por todos los miembros del CACI en el soporte de la edición de sus números.

Inicialmente necesitábamos editoriales, revisiones y casos clínicos de manera que despertara progresivamente el interés de todos nuestros colegas y también de la Cardiología Clínica.

Posteriormente tuvimos artículos especiales, incluyendo varios consensos, artículos de debate y puestas de actualidad, en los que contamos con la colaboración inestimable de intervencionistas importantes desde dentro y fuera de nuestro país.

Con todo este armamentarium, entre todos pudimos lograr que la RACI se encuentre indexada en dos importantes buscadores como Latindex y Google Scholar, este último recientemente.

Es sabido que el fin último de toda revista de cardiología relacionada con una comunidad científica, además de ser el vocero natural de aquella, es la indexación en el más prestigioso buscador médico cual es PubMed, hecho que debe ser nuestro propósito final y más ambicioso.

Nos toca competir con dos importantes revistas científicas de mucho mayor trayectoria que la nuestra y son los organismos científicos de las dos sociedades cardiológicas de nuestro país: SAC y FAC que sin duda tienen ventaja por historia sobre el CACI y la RACI.

Con esa finalidad es que este año tratamos de llegar fuera de los bordes de la especialidad buscando que la mayor cantidad de cardiólogos clínicos puedan tener acceso a la RACI, ya sea en su versión impresa o digital. Para esto se realizó, junto con la secretaria del CACI, una búsqueda mayor de cardiólogos clínicos con acceso a la Revista; igualmente les pedimos a todos los integrantes del CACI aportar nombres de profesionales cercanos a ellos que tuviesen interés en recibirla. Nuestra secretaria está a disposición de todos ustedes. Esta introducción no viene sola, sino que está acompañada por un pedido, que creo es requisito fundamental para una indexación más ambiciosa: nos referimos a la mayor presencia de artículos originales, idealmente dos por número; pero necesitaríamos al menos uno en cada edición para seguir avanzando.

Les pedimos a todos los miembros hacer un esfuerzo para que esto se pueda convertir en realidad, si no en forma inmediata, por lo menos en el mediano plazo. Este es un punto que no podremos obviar si queremos alcanzar nuestro propósito último.

En el presente número se publican dos artículos originales (en el año veníamos con un promedio de uno por número) y esperamos que ello se pueda continuar con el aporte de todos los Jefes de Servicio a lo largo y ancho de nuestro país.

Muchas gracias.

Alfredo E Rodriguez MD,PhD,FACC,FSCAI

Editor en Jefe Revista RACI 